in pain scores in favour of the Treatment group $(\mathrm{p}=0.08)$ (Figure 1). There were no significant differences in terms of the percentage of responders $(p=0.32)$, or patients with LDA $(p=0.50)$ between the 2 groups at follow up. There were no significant differences in pain scores between groups at 3 and 6 months post-injection.

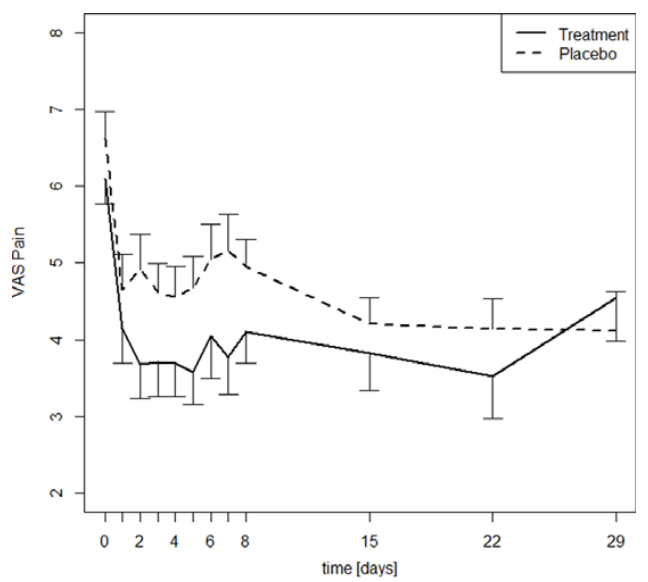

Conclusions: Local corticosteroid injection in the management of GTPS is only marginally effective for a few weeks. Given the lack of long-term improvement and the potential for cortisone-related side-effects, this intervention is of limited benefit.

Disclosure of Interest: None declared

DOI: 10.1136/annrheumdis-2017-eular.3458

\section{OP0272 CHRONIC LOW BACK PAIN AND ANXIETY: SIGNIFICANT DECREASE WITH GLUCOSAMINE-CHONDROITIN SULFATE TREATMENT IN A LARGE, COMMUNITY-BASED, PILOT, OPEN PROSPECTIVE INTERVENTIONAL STUDY}

G. Singh ${ }^{1}$, L. Alekseeva ${ }^{2}$, D. Goriachev ${ }^{3}$, A. Barinov ${ }^{3}$, E. Nasonov ${ }^{2}$, A. Mithal ${ }^{4}$ ${ }^{1}$ Gastroenterology and Hepatology, Stanford University, Woodside, United States; ${ }^{2}$ State NII of Rheumatology of Russian Academy of Sciences; ${ }^{3}$ First Moscow State University, Moscow, Russian Federation; ${ }^{4}$ ICORE, Woodside, United States

Background: Low back pain (LBP) is associated with 2.3, 2.2, and 1.6 times greater odds for mood disorders, anxiety disorders and alcohol abuse respectively (1). Continued anxiety may lead to a state of "learned helplessness", and both can propagate in a vicious cycle. Glucosamine-chondroitin sulfate (GCS) combination is widely used in the treatment of OA; however there are few prospective studies of its therapeutic merits in LBP.

Objectives: To study the efficacy of GCS in the decreasing anxiety in patients with chronic LBP in a large open pilot prospective study.

Methods: We enrolled patients $40-65$ years of age who had LBP for $>12$ weeks with pain intensity $>3$ on a $0-10$ point VAS in a single-arm, open-label prospective interventional study. Major exclusion criteria were the presence of fibromyalgia, spondylolisthesis, and alcohol and/or drug abuse. All patients were treated with ARTRA (combination glucosamine hydrochloride $500 \mathrm{mg}$ - chondroitin sulfate $500 \mathrm{mg}$ in tablet form; Unipharm Inc.) at a dose of $1 \mathrm{tab}$ bid for the first month and then 1 tab daily for the next two months. The primary endpoint was pain intensity as measured on a $0-10$ point VAS. Secondary endpoints included anxiety levels measured by Spielberger's State Trait Anxiety Inventory (STAI) adapted for Russia by Khanin (2). STAl evaluates the current "state" of anxiety, asking how respondents feel "right now," using items that measure subjective feelings of apprehension, tension, nervousness, worry, and activation/arousal of the autonomic nervous system as well as aspects of "anxiety proneness," including general states of calmness, confidence, and security ("trait"). Scores for each scale range from 20 to 80 , with higher scores indicating greater anxiety.

Results: A total of 8,598 subjects (mean age 52.1 years, $67.3 \%$ women, mean BMI 27.4) were enrolled in the study, and formed the intent-to-treat (ITT) population. All but 95 subjects $(1.1 \%)$ completed the study. Previously-reported ITT analysis with worst observation carried forward showed an improvement in pain at rest from mean $( \pm S D)$ of $5.2 \pm 1.9$ at study entry to $1.4 \pm 1.6$ at 3 months $(p<0.0001)$. Pain at movement decreased from $6.8 \pm 1.6$ to $2.2 \pm 1.8(p<0.0001)$. There was a strong correlation between increasing baseline STAI scores and baseline pain at rest and movement (both $p<0.0001$ ). After 12 weeks of GCS treatment, STAI "state" anxiety scores dropped from $49.3(95 \% \mathrm{Cl} 49.1$ to $49.6)$ to $35.8(95 \% \mathrm{Cl} 35.6-36.0)(\mathrm{p}<0.0001)$. A similar reduction was seen in "trait" anxiety scores from $48.3(95 \% \mathrm{Cl} 48.0-48.5)$ to $39.6(95 \% \mathrm{Cl} 39.3-39.8)$ $(p<0.001)$.

Conclusions: Although open and uncontrolled, this large pilot community-based study shows dramatic reductions in pain and anxiety (both "state" and "trait") in patients with LBP treated with GCS. With its benign safety profile, GCS therapy deserves serious evaluation in the management of LBP in a prospective randomized double-blinded clinical trial.
References:

[1] Demyttenaere, K., et al., Mental disorders among persons with chronic back or neck pain. Pain, 2007. 129:332-42.

[2] Spielberger, C. D. (1989). State-Trait Anxiety Inventory: A comprehensive bibliography. Palo Alto, CA: Consulting Psychologists Press.

Disclosure of Interest: G. Singh Grant/research support from: Unipharm Inc., L. Alekseeva: None declared, D. Goriachev Consultant for: Unipharm Inc., A. Barinov: None declared, E. Nasonov: None declared, A. Mithal: None declared DOI: 10.1136/annrheumdis-2017-eular.2642

\section{OP0273 A RETROSPECTIVE DATABASE STUDY OF ONE-YEAR ADEHERNCE AND PERSISTENCE WITH PHARMACOLOGICAL THERAPY AMONG FIBROMYALGIA PATIENTS IN ISRAEL}

D. Weitzman ${ }^{1,2}$, D. Ben-Ami Shor ${ }^{2,3}$, S. Dahan ${ }^{2,4}$, Y. Bar-On ${ }^{5}$, V. Shalev ${ }^{1,2}$, G. Chodick ${ }^{1,2}, \mathrm{H}$. Amital ${ }^{2,4}$. ${ }^{1}$ Epidemiology and Database Resaerch, Maccabitech, Maccabi Healthcare Services; ${ }^{2}$ Sackler Faculty of Medicine, Tel Aviv University, Tel Aviv; ${ }^{3}$ Department of Gastroenterology; ${ }^{4}$ Department of Medicine B, Zabludowicz Center for Autoimmune Diseases, Sheba Medical Center, Tel Hashomer; ${ }^{5}$ Department of Medicine E, Tel-Aviv Sourasky Medical Center, Tel Aviv, Israel

Background: Fibromyalgia (FM) is a chronic debilitating disorder characterized by widespread musculoskeletal pain often accompanied by fatigue, allodynia and hyperalgesia. Literature is scarce regarding adherence to pharmacologic treatments available for FM patients.

Objectives: To assess one-year persistence and adherence with therapy among patients with FM and to identify factors associated with therapy discontinuation. Methods: Using the comprehensive computerized database of Maccabi Healthcare Services, a large healthcare services provider in Israel, all adults ( $\geq 21 \mathrm{yrs}$ ) diagnosed with FM between 2008 and 2011 were identified. FM medications included the anti-convulsant pregabalin, SSRI/SNRI and tricyclic antidepressants. Time to treatment discontinuation, defined as a gap of $\geq 120$ days in medication supply days, and proportion of days covered (PDC) with FM-specific therapies during one year from the first dispense were analyzed. Multivariable logistic regression models were constructed to analyze factors associated with low (PDC $<20 \%$ ) and high (PDC $\geq 80 \%$ ) adherence.

Results: Overall 3932 eligible FM patients were identified, $88.7 \%$ females, mean) SD (age $=49.2$ (12.7). Pre-diagnosis use of medications of interest was documented in $41 \%$ of the patients. Of the remaining $2312,56.1 \%$ were issued a prescription in the year following diagnosis and $45.0 \%$ dispensed at least on medication. One-year discontinuation reached $79.3 \%$ overall, and was highest for tricyclic antidepressants and lowest for SSRI/SNRI antidepressants (Table 1). Over one half of the patients $(60.5 \%)$ were poorly adherent $(\mathrm{PDC}<20 \%)$ during the year and only $9.3 \%$ were highly adherent (PDC $\geq 80 \%$ ). Low adherence was less prevalent among patients diagnosed with migraines (OR=0.62, 95\% $\mathrm{Cl}: 0.48-$ $0.80)$ or with both depression and anxiety $(\mathrm{OR}=0.55 ; 0.40-0.76)$. High adherence was positively associated with socio-economic status ( $p$-for-trend=0.022).

Table 1. Medications prescribed and dispensed in the first year from diagnosis, proportion discontinuing and time to discontinuation in the year following first dispense $(\mathrm{N}=1296)$

\begin{tabular}{|c|c|c|c|c|}
\hline \multirow[t]{2}{*}{ Drug group } & \multirow{2}{*}{$\begin{array}{l}\text { Prescribed } \\
\mathrm{N}(\%)\end{array}$} & \multirow{2}{*}{$\begin{array}{c}\geq 1 \text { dispense } \\
\mathrm{N}(\%)^{\star}\end{array}$} & \multicolumn{2}{|r|}{ Discontinued } \\
\hline & & & $\mathrm{N}(\%)^{\star \star}$ & $\begin{array}{c}\text { Days to discontinuation } \\
\text { Median (IQR) }\end{array}$ \\
\hline Anti-Convulsants & $313(24.1 \%)$ & $228(72.8 \%)$ & $186(81.6 \%)$ & $30(30-106)$ \\
\hline SSRI/SNRI antidepressants & $606(46.7 \%)$ & $471(77.7 \%)$ & $347(73.7 \%)$ & $41(30-171)$ \\
\hline Tricyclic antidepressants & 767 (59.1\%) & $601(78.4 \%)$ & $547(91.0 \%)$ & $30(30-90)$ \\
\hline Any drug & $1296(100 \%)$ & $1041(80.3 \%)$ & 825 (79.3\%) & $40.5(30-146)$ \\
\hline
\end{tabular}

${ }^{*}$ Percent of patients with at least one dispense out of those prescribed, e.g. $228 / 313 \times 100=72.8 \%$ for anti-epileptic drugs. ${ }^{*} \%$ of those with $\geq 1$ dispense.

Conclusions: Persistence and adherence with FM therapy in the year following diagnosis is remarkably low. Further research is needed to assess ways to improve continuation with therapy among FM patients.

Disclosure of Interest: None declared

DOI: 10.1136/annrheumdis-2017-eular.4578

\section{OP0274 FIBROMYALGIA IN REAL LIFE: A NATIONAL FRENCH WEB-BASED SURVEY IN 4516 PATIENTS}

F. Laroche ${ }^{1}$, J. Guérin ${ }^{1}$, D. Azoulay ${ }^{1}$, J. Coste ${ }^{2}$, S. Perrot ${ }^{3}$. ${ }^{1}$ Pain Department, Hospital university Saint Antoine, ${ }^{2}$ Biostatistics, Hospital University Hotel Dieu; ${ }^{3}$ Pain Department, Hospital University Cochin, Paris, France

Background: Fibromyalgia (FM) is the most frequent widespread chronic pain disorder (1,6\% of the French population) (1). The medical and socioeconomic burden is high and severity depends on medical status and symptoms as defined by the OMERACT criteria (2). Most of the studies are performed in specialized centers, recruiting the most severe patients, but very few data exist on its real impact on daily life.

Objectives: The aims were to collect demographic data, symptoms, function, diagnosis, management strategies and health care utilization in real life, in a large population, and to determine clusters of patients. 